This is an electronic reprint of the original article. This reprint may differ from the original in pagination and typographic detail.

Author(s): Sakari, Ritva; Era, Pertti; Rantanen, Taina; Heikkinen, Eino

Title: $\quad$ Associations of sensory-motor functions with poor mobility in 75- and 80-year-old people

Year: $\quad 1998$

Version:

Please cite the original version:

Sakari, R., Era, P., Rantanen, T., \& Heikkinen, E. (1998). Associations of sensory-motor functions with poor mobility in 75- and 80-year-old people. Scandinavian Journal of Rehabilitation Medicine, 30(2), 121-127. https://doi.org/10.1080/003655098444237

All material supplied via JYX is protected by copyright and other intellectual property rights, and duplication or sale of all or part of any of the repository collections is not permitted, except that material may be duplicated by you for your research use or educational purposes in electronic or print form. You must obtain permission for any other use. Electronic or print copies may not be offered, whether for sale or otherwise to anyone who is not an authorised user. 


\title{
ASSOCIATIONS OF SENSORY-MOTOR FUNCTIONS WITH POOR MOBILITY IN 75- AND 80-YEAR-OLD PEOPLE
}

\author{
Ritva Sakari-Rantala, PT, MSc, ${ }^{1}$ Pertti Era, $\mathrm{PhD},{ }^{1,2}$ Taina Rantanen, $\mathrm{PhD}^{1}$ and Eino Heikkinen, MD, $\mathrm{PhD}^{1}$ \\ From the ${ }^{1}$ Department of Health Sciences and the Finnish Centre for Interdisciplinary Gerontology, University of \\ Jyväskylä, and ${ }^{2}$ Metitur Limited, Jyväskylä, Finland
}

\begin{abstract}
This study investigated the associations of sensory-motor functions with mobility in elderly people. All 75- and 80-year-old residents of the city of Jyväskylä, Finland, were invited to take part in the study. A total of $617(93 \%)$ persons were interviewed, and $500(\mathbf{7 5 \%})$ took part in laboratory examinations. Self-reported mobility was recorded during the interview. Basic mobility functions (maximal walking speed and stairmounting ability) and sensory-motor functions (maximal isometric muscle strength, standing balance, reaction time and visual acuity) were measured in the laboratory. Multivariate analyses showed that poor sensory-motor functions were significantly associated with poor performance in basic mobility functions and that poor performance in basic mobility functions was associated with self-reported disability in mobility. The associations discovered were consistent with models of the disablement process. Muscle strength, balance, reaction time and vision all have individual significance for mobility, underlining the need for multifactorial approaches in prevention and rehabilitation.
\end{abstract}

Key words: disability; elderly; functional limitation; impairment; mobility; sensory-motor function.

\section{INTRODUCTION}

Mobility is determined and coordinated by musculoskeletal, cardiorespiratory, sensory and neural systems. For example, without sufficient knee extensor strength it is not possible to climb stairs $(25,35)$. The maintenance of postural stability is a crucial requirement in walking because the body is actually in a continual state of dynamic imbalance (22). During locomotion, vision is needed for monitoring and analysing the location and movement of the body as well as the environmental conditions to which the motor system should respond $(18,28)$. The ability to react quickly is needed for the avoidance of obstacles in the gait path (5).

The sensory-motor background factors of mobility are impaired by aging, chronic diseases and inactivity. The decline of mobility that typically follows with old age can be described with models of the disablement process $(24,32)$. Nagi $(24)$ and Verbrugge \& Jette (32) suggest that different kinds of pathologies cause different impairments at the organ system level (for example, dysfunctions and abnormalities in musculoskeletal and cardiovascular systems). These impairments usually lead to basic functional limitations (for example, restrictions in basic physical actions such as ambulation, reach, stoop), which often cause disability in everyday life (for example, difficulties in activities of daily living in the person's own living environment).

This cross-sectional study set out to investigate the associations of sensory-motor functions that are essential for locomotion, such as muscle strength, balance, reaction time and vision, with the mobility of elderly people. At the same time the purpose was to establish whether the associations uncovered are consistent with the assumed pathway of the disablement process. The model of the disablement process $(24,32)$ was modified to consider mobility and its sensory-motor background factors at the three last levels (impairments, functional limitations and disability). To date, only a few studies have analysed more than two consecutive levels of the model simultaneously (e.g. 14, 17), and none of these have focused exclusively on the mobility of elderly people.

\section{METHODS}

\section{Subjects}

This study is part of the EVERGREEN project, a major research programme focusing on the health and functional 
capacity of the elderly population of the city of Jyväskylä, central Finland (13). The study groups comprised all people born in 1910 and 1914. In $1989,119(95.2 \%)$ men and 236 $(91.8 \%)$ women from the younger age group (75-year-olds) took part in interviews carried out in their homes. Of the invited and eligible persons, $104(83.2 \%)$ men and 191 (74.3\%) women came to laboratory examinations about 2 weeks later. In 80-year-old men and women in 1990, the corresponding figures were $74(96.1 \%)$ and $188(90.4 \%)$ for the interviews and $60(77.9 \%)$ and $145(69.7 \%)$ for the laboratory examinations. Poor health was one of the major reasons why some people were unable to participate in the laboratory examinations. A significantly greater proportion of those who could not attend the laboratory examinations needed help in their mobility ( $p<0.05$ in every subgroup). Although the majority of the participants lived in the community (only 9 lived in institutions), there was considerable variation among the subjects in terms of chronic morbidity. For example, the study population included persons with several chronic diseases (maximum 8 ) and those without any diagnosed disease.

\section{Assessment procedures}

The interview comprised issues on sociodemographic factors, Activities of Daily Living (ADL) and living conditions. In addition, the subjects completed a health questionnaire at home. The laboratory examinations included a medical examination, measurement of height and weight, performance tests of mobility, measurements of sensory and psychomotor functions and muscle strength tests.

Mobility index. The disability level in the disablement process $(24,32)$ was represented by a mobility index, which indicated how mobility problems were manifested in the subject's everyday life. The index was formed on the basis of the subject's self-reported ability to get about indoors and outdoors and to negotiate stairs. These questions were part of the ADL Scale (2). The subjects were asked whether they are able to do the task, whether they get tired when doing the task, whether the task takes more time than before and whether they need help (alternatives yes and no). The index consisted of three categories. The subjects who reported need of help in any of the three tasks were allocated to the first category, the subjects who reported slowness or tiredness in at least one task but no need of help to the second category, and those participants who were able to perform the tasks without difficulty to the third category. The inter-rater and intrarater reliability of the original three questions has been evaluated and found to be high in a Danish sample (4).

In order to validate the mobility index, information about 5-year mortality was obtained from the register of the province of Central Finland. Self-rated health was asked in the health questionnaire (scaling: $1=$ very good, $2=\operatorname{good}$, $3=$ satisfactory, $4=$ poor, $5=$ very poor) and the prevalence of chronic diseases (lasting more than 3 months) was obtained at the medical examination. In logistic regression, adjusted for age and sex, the probability of dying was seven times greater among those who reported need of help [odds ratio (OR) 7.07, confidence interval (CI) $3.21-15.62$ ] and two times greater among those who reported slowness or tiredness (OR 1.97, CI 1.04-3.73) when compared to those who had no difficulties. Similarly, the OR for rating one's health poor was 6.94 in the "need of help" group (CI 1.99-
24.17) and 4.39 in the "slowness/tiredness" group (CI 2.44 7.90). The OR for having three or more chronic diseases was 5.91 in the "need of help" group (CI 2.86-12.18) and 3.00 in the "slowness/tiredness" group (CI 1.83-4.91).

Basic mobility functions. The functional limitations level in the disablement process $(24,32)$ was interpreted as basic mobility functions at the whole body level, such as stair-mounting ability and maximal walking speed. In the stair-mounting test, the highest step that the subject could mount without support in a single step was recorded (step heights of $0,10,20,30,40$, and $50 \mathrm{~cm}$ ) $(1,25)$. Because taller persons have greater leg length and thus more favourable working conditions for the lower extremity joints and muscles during stair-mounting, the result was adjusted for height. After dividing the original value by the subject's height, it was multiplied by the mean height of all participants. The new values were then reclassified as $0,10,20,30,40$ and $50 \mathrm{~cm}$, with cut points in the middle of the class intervals. The reclassified values were used in the multivariate models. Maximal walking speed over 10 metres was measured by a stopwatch in the laboratory corridor. Walking aids were allowed if the subject normally used them when walking. The corridor was illuminated by standard fluorescent lamps.

Sensory-motor functions. Sensory-motor functions were assumed to represent the impairments at body system level in the disablement process $(24,32)$. These functions do not indicate the impairments per se, but rather the functional consequences of impairments of separate organ systems. Maximal isometric muscle strength was measured for knee and trunk extensors by dynamometers (12). Knee extension strength was measured in a sitting position, knee fixed $60^{\circ}$ from full extension, and trunk extension in a standing position. The strength/weight ratio was calculated and used in the analyses. Standing balance was measured by a computerized force platform system (8). The subject stood as still as possible on the platform for 40 seconds, feet comfortably apart and hands on hips, the first test with eyes open and the second with eyes closed. The speeds of antero-posterior and mediolateral movement of the centre of forces were used in the analyses, adjusted according to the subject's height. The balance variables in the final multivariate models differed according to the age group. Simple reaction time for visual stimuli was measured for the dominant hand (7). The subject was seated in front of the timing device, with the index finger on the rest button. After noticing the light, the subject moved the finger as quickly as possible from the rest button and switched the light off from a nearby button. Visual acuity with lens correction (if needed) was measured by a computerized refractometer (Topcon RMA2300). Because of technical problems, the reaction time and balance results could not be obtained for all subjects in the younger age group. However, this had no systematic effect on the results (8).

\section{Statistical methods}

The model of the disablement process $(24,32)$ guided the selection of the variables and the analytical methods. Crosstabulation with $\chi^{2}$ testing was used in bivariate analyses of discrete variables; Student's $t$-test was used in the case of continuous variables. Logistic regression was used for the validation study of the mobility index. Polychoric (between discrete variables), polyserial (between discrete and con- 
tinuous variables) and Pearson's product moment correlation coefficients were calculated by PRELIS (29) (tables not shown). On the basis of these correlations, LISREL models (15) were created separately for each age and sex group. The sensory-motor variables indicated the independent variables ( $x$-variables), and the mobility variables indicated the dependent variables ( $y$-variables). Because of the skewness of the results in the stair-mounting test among men, the three lowest categories were combined. To achieve normally distributed values for further analyses, a few extreme cases were excluded from the balance and reaction time results ( 2 men and 9 women).

\section{RESULTS}

The mobility index indicated that there were some minor differences in self-reported mobility between age and sex groups (Table I). The women in the older age group needed help in their mobility functions more often than their counterparts in the younger age group $(p=0.006)$. Walking aids were used by 34 persons $(12 \%)$ in the 75 -year-olds and by 39 persons $(23 \%)$ in the 80 -year-olds.

About $69 \%$ of the participants were unable to mount even the $10 \mathrm{~cm}$ high step; their result was therefore zero (Table II). In men, a ceiling effect was evident and the distributions were skewed. About $75 \%$ of the 75 -year-old men and about $60 \%$ of the $80-$ year-old men were able to mount the highest step. In women, the corresponding figures were $28 \%$ and $20 \%$. The differences between men and women were statistically significant $(p<0.001)$. After adjusting the results according to the subject's height, the difference between the sexes was slightly reduced.

Table I. Mobility index in 75 - and 80-year-old men and women (the variables were: getting about indoors, getting about outdoors and negotiating stairs)

\begin{tabular}{|c|c|c|c|c|}
\hline \multirow[b]{2}{*}{ Mobility } & \multicolumn{2}{|c|}{ 75-year-olds } & \multicolumn{2}{|c|}{ 80-year-olds } \\
\hline & $\begin{array}{l}\text { Men } \\
n(\%)\end{array}$ & $\begin{array}{l}\text { Women } \\
n(\%)\end{array}$ & $\begin{array}{l}\text { Men } \\
n(\%)\end{array}$ & $\begin{array}{l}\text { Women } \\
n(\%)\end{array}$ \\
\hline Needs help* & $8(8.0)$ & $14(7.6)$ & $8(16.7)$ & $22(18.3)$ \\
\hline Slowly/tired $\uparrow$ & $55(55.0)$ & $121(65.8)$ & $26(54.2)$ & $78(65.0)$ \\
\hline $\begin{array}{l}\text { Without } \\
\text { difficulties }\end{array}$ & $37(37.0)$ & $49(26.6)$ & $14(29.2)$ & $20(16.7)$ \\
\hline Total & 100 & 184 & 48 & 120 \\
\hline
\end{tabular}

* Needs help in at least one task;

$\dagger$ reported slowness or tiredness in at least one task;

\$ did not report slowness/tiredness/need of help in any task.
Six men born in 1914 and 2 men born in 1910 were reallocated from the $50 \mathrm{~cm}$ group to the $40 \mathrm{~cm}$ group. One woman in both age groups was moved from the $40 \mathrm{~cm}$ group to the $50 \mathrm{~cm}$ group. The maximal walking speed of the 75-year-old men was $1.78 \mathrm{~m} / \mathrm{s}$ ( \pm 0.51 ) and for the 75 -year-old women $1.48 \mathrm{~m} / \mathrm{s}$ ( \pm 0.36 ). In 80 -year-olds the maximal walking speed was $1.48 \mathrm{~m} / \mathrm{s}( \pm 0.54)$ in men and $1.27 \mathrm{~m} / \mathrm{s}( \pm 0.33)$ in women. Women were significantly slower than men $(p<0.001)$, and the 80 -year-olds were significantly slower than 75 -year-olds $(p<0.001)$.

Figure 1 shows the LISREL models for 75-year-old men and women and for 80-year-old men and women. Separate analyses were performed on the basis of age and sex, as these factors affected most of the variables studies. Although the models differed somewhat, a similar structure fitted all groups. Of the sensorymotor factors, muscle strength, standing balance and simple reaction time explained basic mobility functions in all models. Knee extension strength explained both maximal walking speed and stair-mounting ability in 75 -year-olds and 80 -year-old men. In $80-$ year-old women, knee extension strength explained only maximal walking speed. In the models for the women, trunk extension strength also explained maximal walking speed. Visual acuity explained basic mobility functions in 75-year-old women and 80-year-old men. All the directions of the associations were consistent with our expectations (poor sensorymotor functions explained poor results in basic mobility function tests).

Sensory-motor functions explained $39-46 \%$ of the variation in maximal walking speed in the models for women and 75-year-old men. In 80-year-old men, $63 \%$ of the variation in maximal walking speed was explained by sensory-motor functions and stair-

Table II. Stair-mounting ability in 75- and 80-yearold men and women (absolute values)

\begin{tabular}{|c|c|c|c|c|}
\hline \multirow[b]{2}{*}{ Step height } & \multicolumn{2}{|c|}{ 75-year-olds } & \multicolumn{2}{|c|}{ 80-year-olds } \\
\hline & $\begin{array}{l}\text { Men } \\
n(\%)\end{array}$ & $\begin{array}{l}\text { Women } \\
n(\%)\end{array}$ & $\begin{array}{l}\text { Men } \\
n(\%)\end{array}$ & $\begin{array}{l}\text { Women } \\
n(\%)\end{array}$ \\
\hline $0 \mathrm{~cm}$ & $6(5.9)$ & $13(6.8)$ & $4(8.5)$ & $8(6.5)$ \\
\hline $10 \mathrm{~cm}$ & $2(2.0)$ & $9(4.7)$ & 0 & $3(2.4)$ \\
\hline $20 \mathrm{~cm}$ & $2(2.0)$ & $20(10.5)$ & 0 & $16(13.0)$ \\
\hline $30 \mathrm{~cm}$ & $11(10.9)$ & $46(24.2)$ & $6(12.8)$ & $37(30.1)$ \\
\hline $40 \mathrm{~cm}$ & $5(5.0)$ & $48(25.3)$ & $9(19.1)$ & $35(28.5)$ \\
\hline $50 \mathrm{~cm}$ & $75(74.3)$ & $54(28.4)$ & $28(59.6)$ & $24(19.5)$ \\
\hline
\end{tabular}



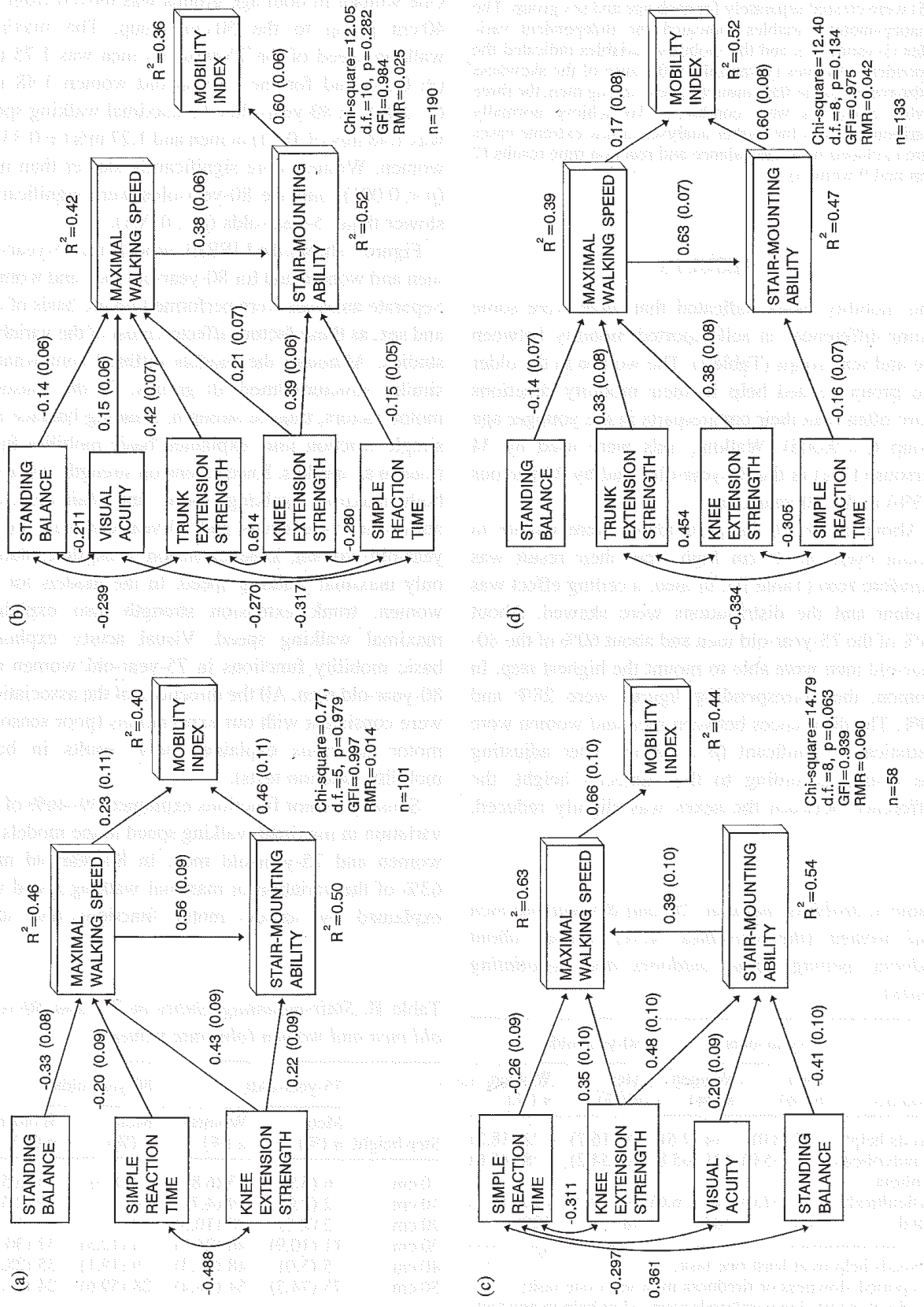
mounting ability: In the models for women and $75-$ year-old men, sensory-motor functions and maximal walking speed explained $47-52 \%$ of the variation in stair-mounting ability. In 80-year-old men, sensorymotor functions explained $54 \%$ of the variation in stair-mounting ability.

Basic mobility functions were associated with the mobility index in all models. Stair-mounting ability and maximal walking speed correlated strongly with each other, which was probably the reason that the effects of these variables on the mobility index were mediated through one or the other in 75-year-old women and 80-year-old men. The direction of the associations was as expected: poor stair-mounting ability and slow walking speed explained the poor result in the mobility index. Of the variation in the mobility index, 36-52\% was explained in the models. In addition, maximal walking speed had a significant indirect effect on the mobility index (not shown in Fig. 1): in 75-year-old men the coefficient was 0.26 and the standard error 0.07 , in 75-year-old women 0.23 and 0.04 and in 80-year-old women 0.38 and 0.07 , respectively. In 80 -year-old men; stair-mounting ability had a significant indirect effect on the mobility index (coefficient 0.26 , standard error 0.08 ). According to the $\chi^{2}$ tests as well as other fit measures, all the models fitted well to the data.

\section{DISCUSSION}

The results of this study indicate that sensory-motor impairments are significantly associated with basic functional limitations and, further, that basic functional limitations are significantly associated with poor mobility in 75- and 80-year-old men and women. The associations discovered are consistent with our framework, which was modified from the model of the disablement process $(24,32)$. This was ascertained by multivariate analyses, which showed similar structures across age and sex groups. However, given the limitations of the cross-sectional research design, the results must be interpreted with caution. Further studies applying longitudinal procedures are needed.

The rates of participation in both the interviews and the laboratory examinations were very high, which makes the generalizability of the results exceptionally good. However, the subjects with the highest level of impairment were unable to take part in every phase of the study, which is common in mobility studies that include performance tests.

The explanative strength of the models was good. However, there was still some unexplained variation which may be due, among other things, to our failure to capture in the framework used all the possible impairments caused by aging processes, inactivity and chronic conditions. For example, no evaluations were made of pain or range of motion in the joints of the lower extremities.

The mobility index used in this study indicated roughly the same level of disability in mobility as have previous, comparable population studies $(3,30)$. The results for stair-mounting ability and maximal walking speed correspond to previous results for persons of approximately the same age $(3,10)$. These performance tests have been found to correlate with poor self-reported mobility $(3,11)$, as was the case in the present study.

Poor knee extension strength was a strong determinant of poor mobility in this study. Similar results have been obtained in previous studies concerning both walking speed $(20,27)$ and stair-mounting ability $(25,27)$. When climbing stairs, the climber has to place the foot onto the elevated surface of the stair and bring the centre of mass over the new base of support (16). In our analyses, the contribution of anthropometric properties in this task was taken into account by adjusting stair-mounting ability for height and muscle strength for body mass. Among women in this : study, the strength of trunk extensors : also explained maximal walking speed in the models. It is obvious that control of the movements of the upper body (head, arms and trunk) during the stride cycle

\footnotetext{
Fig. 1. The sensory-motor determinants of mobility functions by LISREL models in (a) 75-year-old men, (b) 75 -yearold women, (c) 80-year-old men and (d) 80-year-old women. The straight arrows indicate significant associations and their directions between variables. The coefficients and their standard errors (in brackets) are shown. In reaction time and balance variables higher values mean poorer performance, which causes negative coefficients. The curved arrows represent significant correlations between independent variables. The $\mathrm{R}^{2}$ values indicate the amount of variation in the dependent variables explained by the background factors in the model. GFI $=$ goodness of fit index, $R M R=$ root mean square residual. In (a) and (b), standing balance is the speed of antero-posterior movement of the centre of forces, eyes closed. In (c) and (d), standing balance is the speed of antero-posterior movement of the centre of forces, eyes open.
} 
requires significant involvement of the trunk musculature.

Previous researchers have found mainly moderate but significant associations between standing balance measured by force platform and mobility in elderly people $(19,23)$, although there are some exceptions (10). In the present study, the associations of standing balance with stair-climbing capacity (in 80 -year-old men) and maximal walking speed (in women and in 75-year-old men) were significant. The slower walking speed in old age results from shorter stride length and longer duration of the double support phase (9). These changes in the gait pattern seem to be caused by poorer balancing abilities and reduced muscle strength (34).

Simple reaction time, which requires relatively low-level central nervous system processing, has been found to be an important determinant of postural balance $(7,21)$. In this study, both standing balance and simple reaction time remained in the models as significant determinants of mobility functions. Similarly, Lord et al. (20) found that simple reaction time was associated with walking speed in multivariate analyses.

Visual acuity significantly explained mobility functions in 75-year-old women and in 80-year-old men. Similar results have been reported previously $(20,26)$. The importance of visual acuity during walking is readily apparent. For instance, in the middle of the swing phase of the stride cycle the toes are not raised more than about $1 \mathrm{~cm}$ off the ground (33). Thus, even minor ruggedness of the terrain needs to be seen properly to prevent stumbling.

The results of this study indicate that both stairmounting ability and maximal walking speed are important dimensions behind mobility problems in everyday life. The measurement of these functions helps to identify persons with mobility problems, even in an early stage (11). The assessment of sensory-motor background factors gives an insight into the probable effectors and modifiers of mobility problems and, consequently, provides valuable clues for planning treatment.

The levels of most sensory-motor and basic mobility functions differ between age and sex groups, which was why the analyses were carried out separately in each group. In spite of these basic differences, the roles of the background factors were very similar among the groups and essentially the same structure could be seen in all models. This suggests that both in elderly men and women the same factors should be examined when attempting to identify people at risk and prevent the deterioration of mobility.

It has been shown in two recent studies $(6,20)$ that age-related dysfunctions in mobility are associated with impairments in multiple physiological domains. As Vandervoort et al. (31) state, this multifactorial nature of mobility dysfunction in the elderly population requires comprehensive assessment and treatment approaches. The results of the present study suggest that the sensory-motor functions studied have individual importance for mobility and that they do not compensate each other. This means that not only muscle strength but also other aspects such as balance, reaction time and vision should be taken into account when planning and implementing interventions which aim to improve mobility. Many of these factors are modifiable by physical exercise or other means of prevention and rehabilitation.

\section{ACKNOWLEDGEMENTS}

This study was supported by grants from the Academy of Finland, the Ministry of Education, the Ministry of Social Affairs and Health, and the city of Jyväskylä. The authors wish to thank Esko Leskinen, PhD, and Markku Kauppinen, $\mathrm{MSc}$, for statistical advice and Jack Guralnik, PhD, for valuable suggestions in planning the analytical approach. Detailed correlation tables for each age and sex group are available from the first author.

\section{REFERENCES}

1. Aniansson, A. Rundgren, $\AA$. \& Sperling, L.. Evaluation of functional capacity inactivities of daily living in 70 year-old men and women. Scand J Rehabil Med 12; 145-154, 1980.

2. Avlund, K. Kreiner, S. \& Schultz-Larsen, K.: Construct validation and the Rasch model: functional ability of healthy elderly people. Scand J Soc Med 21: 233-245, 1993.

3. Avlund, K. Schroll, M. Davidsen, M. Løvborg, B. \& Rantanen, T.: Maximal isometric muscle strength and functional ability in daily activities among 75-year-old men and women. Scand J Med Sci Sports 4: 32-40, 1994.

4. Avlund, K. Thudium, D. Davidsen, M. \& FuglsangSørensen, B.: Are self-ratings of functional ability reliable? Scand J Occup Ther 2: 10-16, 1995.

5. Chen, H.-C. Ashton-Miller, J. A. Alexander, N. B. \& Schultz, A. B.: Effects of age and available response time on ability to step over an obstacle. J Gerontol 49: M227-M233, 1994.

6. Duncan, P. W. Chandler, J. Studenski, S. Hughes, M. \& Prescott; B.: How do physiological components of 
balance affect mobility in elderly men? Arch Phys Med Rehabil 74. 1343-1349,1993.

7. Era, P. Jokela, J. \& Heikkinen, E. Reaction and movement times in men of different ages: a population study: Percept Mot Skills 63: 111-130, 1986.

8. Era, P. Schroll, M. Ytting, H. Gause-Nilsson, I. Heikkinen, E. \& Steen, B.: Postural balance and its sensory-motor correlates in 75 -year-old men and women-a cross-national comparative study. J Gerontol 51A: M53-M63, 1996.

9. Ferrandez, A.-M. Pailhous, J. \& Durup, M.: Slowness in elderly gait. Exp Aging Res 16: 79-89, 1990.

10. Frändin, K. Sonn, U. Svantesson, U. \& Grimby, G.: Functional balance tests in 76-year-olds in relation to performance, activities of daily living and platform tests. Scand J Rehabil Med 27: 231-241, 1995.

11. Guralnik, J. M. Ferrucci, L. Simonsick, E. M. Salive, M. E. \& Wallace, R. B.: Lower-extremity function in persons over the age of 70 years as a predictor of subsequent disability. N Engl J Med 332: 556-561, 1995.

12. Heikkinen, E. Arajärvi, R.-L. Era, P. Jylhä, M. Kinnunen, V. Leskinen, A.-L. Leskinen, E. Mässeli, E. Pohjolainen, P. Rahkila, P. Suominen, H. Turpeinen, P. Väisänen, M. \& Österback, L.: Functional capacity of men born in 1906-1910, 1926-30 and 1946-50. A basic report. Scand J Soc Med Suppl 33: 1984.

13. Heikkinen, E. Heikkinen, R.-L. \& Ruoppila, I.: Functional capacity and health of elderly people - the Evergreen project. Scand J Soc Med Suppl 53: 1997.

14. Johnson, R. J. \& Wolinsky, F. D.: The structure of health status among older adults: disease, disability, functional limitation and perceived health. J Health Soc Behav 34: 105-121, 1993.

15. Jöreskog, K. G. \& Sörbom, D. LISREL 7: a guide to the program and applications. 2nd ed. SPSS Inc. Chicago, 1989.

16. Konczak, J. Meeuwsen, H. J. \& Cress, M. E.: Changing affordances in stair climbing: the perception of maximum climbability in young and older adults. J Exp Psychol 18: 691-697, 1992.

17. Lawrence, R. H. \& Jette, A. M.: Disentangling the disablement process. J Gerontol 51B: S173-S182, 1996.

18. Lee, D. N. \& Lishman, R.: Visual control of locomotion. Scand J Psychol 18: 224-230, 1977.

19. Lichtenstein, M. J. Burger, M. C. Shields, S. L. \& Shiavi, R. G.: Comparison of biomechanics platform measures of balance and videotaped measures of gait with a clinical mobility scale in elderly women. J Gerontol 45: M49-M54, 1990.

20. Lord, S. R. Lloyd, D. G. \& Keung Li, S.: Sensori-motor function, gait patterns and falls in community-dwelling women. Age Ageing 25: 292-299, 1996.

21. Lord, S. R. \& Ward, J. A.: Age-associated differences in sensori-motor function and balance in community dwelling women. Age Ageing 23: 452-460, 1994.

22. MacKinnon, C. D. \& Winter, D. A.: Control of whole body balance in the frontal plane during human walking. J Biomech 26: 633-644, 1993.

23. Mathias, S. Nayak, U. S. L. \& Isaacs, B.: Balance in elderly patients: the "Get-up and Go" test Arch Phys Med Rehabil 67: 387-389, 1986.

24. Nagi, S. Z. Disability concepts revisited implications for prevention. In Disability in America Toward a National Agenda for Prevention (ed. A. Pope \& A. Tarlov), pp. 309-327. National Academy Press, Washington DC, 1991.

25. Rantanen, T. Era, P. \& Heikkinen, E.: Maximal isometric knee extension strength and stair-mounting ability in 75- and 80-year-old men and women. Scand J Rehabil Med 28: 89-93, 1996.

26. Salive, M. E. Guralnik, J. Glynn, R. J. Christen, W. Wallace, R. B. \& Ostfeld, A. M.: Association of visual impairment with mobility and physical function. J Am: Geriatr Soc 42: 287-292, 1994.

27. Sonn, U. Frändin, K. \& Grimby, G.: Instrumental activities of daily living related to impairments and functional limitations in 70 -year-olds and changes between 70 and 76 years of age. Scand J Rehabil Med 27: 119-128, 1995.

28. Spaulding, S. J. Patla, A. E. Elliott, D. B. Flanagan, J. Rietdyk, S. \& Brown, S.: Waterloo vision and mobility study: gait adaptations to altered surfaces in individuals with age-related maculopathy. Optom Vis Sci 71: 770$777,1994$.

29. SPSS: LISREL 7 and PRELIS. User's guide and reference. SPSS Inc., Chicago, 1990.

30. Strawbridge, W. J. Kaplan, G. A. Gamacho, T. \& Cohen, R. D.: The dynamics of disability and functional change in an elderly cohort: results of the Alameda County study. J Am Geriatr Soc 40: 799-806, 1992.

31. Vandervoort, A. Hill, K. Sandrin, M. \& Vyse, M.: Mobility impairment and falling in the elderly. Physiother Can 42: 99-107, 1990.

32. Verbrugge, L. M. \& Jette, A. M.: The disablement process. Soc Sci Med 38: 1-14, 1994.

33. Winter, D. A.: Foot trajectory in human gait: a precise and multifactorial motor control task. Phys Ther 72: 45$56,1992$.

34. Winter, D. A. Patla, A. E. Frank, J. S. \& Walt, S. E.: Biomechanical walking pattern changes in the fit and healthy elderly. Phys Ther 70: 340-347, 1990.

35. Young, A.: Exercise physiology in geriatric practice. Acta Med Scand Suppl 711: 227-232, 1986.

Accepted June 9, 1997

Address for offprints:

Ritva Sakari-Rantala

Department of Health Sciences

University of Jyväskylä

P.O. Box 35

FI-40351 Jyväskylä

Finland 